\title{
Práticas da equipe de enfermagem no processo de alta do bebê pré-termo
}

\author{
Practices of nursing staff in the process of preterm baby hospital discharge \\ Prácticas del equipo de enfermería en el proceso de alta del bebé prematuro
}

\begin{abstract}
Kayna Trombini Schmidt', Mariélli Terassi", Sonia Silva Marcon"', leda Harumi Higarashi"'I
'Colégio Estadual Cianorte, Curso Técnico de Enfermagem. Cianorte-PR, Brasil.

" Universidade Estadual de Londrina, Curso de Graduação em Enfermagem. Londrina-PR, Brasil.

I"' Universidade Estadual de Maringá, Centro de Ciências Biológicas, Departamento de Enfermagem. Maringá-PR, Brasil.
\end{abstract}

\author{
Submissão: 03-09-2012 Aprovação: 13-11-2013
}

\section{RESUMO}

O objetivo deste estudo foi identificar as estratégias utilizadas pela equipe de enfermagem atuante na unidade neonatal de um hospital-escola, durante o preparo da família para a alta do prematuro. Trata-se de estudo descritivo, com abordagem qualitativa. Os dados foram coletados entre março e junho de 2011, por meio de observação e entrevistas semiestruturadas. Da análise dos discursos emergiram duas categorias temáticas: Orientações e estratégias profissionais no preparo da família para a alta do prematuro e Dificuldades e potencialidades no espaço da atenção neonatal. A principal estratégia referida pelos profissionais foi a inserção precoce da família no processo de cuidar; a dificuldade destacada foi a ausência dos pais durante a internação do filho. As potencialidades e limitações apontadas por este estudo revelaram que o processo da assistência é dinâmico, necessitando de constantes reajustes e adequações para atender efetiva e integralmente o bebê prematuro e sua família.

Descritores: Prematuro; Alta do Paciente; Unidades de Terapia Intensiva Neonatal; Enfermagem Neonatal.

\section{ABSTRACT}

The objective of this study was to identify the strategies used by the nursing team in the neonatal unity care of a school-hospital during the preparation of the family for the premature baby discharge. It is a descriptive study with qualitative approach. The data was collected between March and June 2011, by means of observation and semi-structured interviews. From the discourse analysis two categories appeared: Orientations and professional strategies in preparing the family for the premature baby hospital discharge and Difficulties and potentialities in the neonatal attention space. The main strategy mentioned was the family early insertion in the caring process and the stressed difficulty was the parents' absence during the child's hospital staying. The potentialities and limitations pointed out in this study revealed that the assistance process is dynamic, asking for constant correction and adequacies to effectively and wholly care for the premature baby and its family.

Key words: Infant; Premature; Patient Discharge; Intensive Care Units Neonatal; Neonatal Nursing.

\section{RESUMEN}

El objetivo del estudio fue identificar estrategias utilizadas por el equipo de enfermería actuante en la unidad neonatal de un hospital escuela durante la preparación de la familia para el alta del prematuro. Es un estudio descriptivo, con abordaje cualitativo. Se colectaron datos entre marzo-junio de 2011, por medio de observación y entrevistas semi estructuradas. Del análisis surgieron dos categorías temáticas: Orientaciones y estrategias profesionales en el preparo de la familia para el alta del prematuro; Dificultades y potencialidades en el espacio de atención neonatal. La principal estrategia referida por los profesionales fue la inserción precoz de la familia en el proceso de cuidados. La dificultad destacada fue la ausencia de los padres durante la internación del hijo. Las potencialidades y limitaciones apuntadas por este estudio revelaron que el proceso de asistencia es dinámico, necesitando constantes ajustes y adecuaciones para atender efectiva e integralmente al bebé prematuro y a su familia.

Palabras clave: Prematuro; Alta del Paciente; Unidades de Terapia Intensiva Neonatal; Enfermería Neonatal. 


\section{INTRODUÇÃO}

A incorporação de novas tecnologias e especialização dos profissionais para cuidar de recém-nascidos $(\mathrm{RN})$ de risco propiciou a sobrevivência de bebês prematuros considerados anteriormente como inviáveis ${ }^{(1-2)}$. No ambiente altamente tecnológico da Unidade de Terapia Intensiva Neonatal (UTIN), os profissionais geralmente se encontram envolvidos na execução de cuidados complexos aos recém-nascidos (RN), comprometendo o estabelecimento de relações impessoais, o que pode prejudicar a interação do profissional com a família desses pequenos pacientes ${ }^{(3)}$.

A necessidade de internação do filho na UTIN incita, nos familiares, sentimentos de medo, angústia e impotência perante a iminente possibilidade de óbito do bebê $\hat{e}^{(2)}$. Ao mesmo tempo, o longo período de internação interfere negativamente no fortalecimento do vínculo entre mãe-filho, assim como no desenvolvimento das habilidades da progenitora para o cuidado ao prematuro. A reação da mãe ante os sentimentos negativos aflorados durante a internação do filho é modulada de acordo com o suporte que esta recebe dos profissionais, sendo que, quanto maior o apoio oferecido, menor a ansiedade materna ${ }^{(4)}$.

A preocupação com a garantia da qualidade na assistência voltada para atender às necessidades do binômio mãe e RN desencadeia a necessidade de identificar os problemas subjetivos, para posterior planejamento de ações direcionadas à singularidade de cada caso e aos aspectos biopsicossociais que interferem no processo de aprendizado ${ }^{(5)}$.

Partindo da premissa de que a escuta é um recurso assistencial, a equipe de enfermagem deve direcionar o processo da alta de acordo com as dúvidas e as ansiedades da família nos diferentes momentos, visto que a simples orientação, sem considerar as subjetividades relativas à família e ao $\mathrm{RN}$, repercute no processo de ensino/aprendizagem ineficaz ${ }^{(6)}$.

Para atender às necessidades de aprendizado da família, de modo a capacitá-la para dar continuidade aos cuidados do RN no ambiente domiciliar, é necessário que se desenvolva um processo de planejamento da alta. Este tem por finalidade desenvolver a habilidade dos pais no cuidado com o neonato, diminuir o nível de stress da família, evitar reinternações e identificar recursos comunitários disponíveis para seguimento após a alta hospitalar(7).

A concretização deste estudo se deu a partir da vivência profissional na atenção direta ao recém-nascido pré-termo, e da inquietação provocada pela ausência de uma sistemática de preparo da família para a alta desses neonatos. Desse modo, o objetivo do presente estudo foi identificar as estratégias utilizadas pela equipe de enfermagem atuante na unidade neonatal durante o preparo da família para a alta do prematuro.

\section{METODOLOGIA}

Estudo descritivo, com abordagem qualitativa, realizado em um hospital-escola localizado na região noroeste do Paraná, que realiza atendimentos exclusivamente pelo Sistema Único de Saúde (SUS). A instituição é referência para atendimento de gestantes de risco e conta com uma UTIN, composta por seis leitos e uma Unidade de Cuidados Intermediários Neonatal (UCIN), com quatro leitos. O hospital também disponibiliza três leitos destinados ao alojamento conjunto, para que as mães possam permanecer acompanhando os filhos prematuros em período integral nos dias que antecedem a alta hospitalar. Essa clientela conta ainda com o atendimento do Banco de Leite Humano dentro do hospital que auxilia as puérperas no manejo do aleitamento materno.

A equipe de saúde das unidades neonatais é composta por médicos, enfermeiros, técnicos de enfermagem, fonoaudióloga, fisioterapeutas, assistente social e auxiliar de serviços gerais. Ao todo, atuam nas unidades neonatais prestando assistência direta ao RN e suas famílias, 12 enfermeiros e 14 técnicos de enfermagem, divididos em cinco turnos de trabalho. Durante o dia, o turno é de seis horas e, à noite, a carga horária é de 12 horas, alternadas em esquema de rodízio entre três equipes que se distribuem em noites um, dois e três (sistema 12 por 60 horas). Os pais podem permanecer na unidade das 8 às 22 horas e toda tarde é liberada, por uma hora, a visita de outras pessoas ou familiares.

Os dados foram coletados no período de março a junho de 2011, por meio de observação não participante e entrevistas nos locais de trabalho, conforme agendamento prévio. A observação ocorreu anteriormente às entrevistas, com o propósito de possibilitar a verificação da existência ou não de rotinas de assistência ao binômio prematuro e família, no que tange ao preparo dos pais para a alta, bem como delinear como se dá essa assistência e o registro das atividades em questão.

As observações ocorreram nos meses de março e abril de 2011 e contemplaram os turnos da manhã, tarde e noite. Os prontuários dos prematuros foram consultados, em busca de anotações e registros acerca das orientações e das ações realizadas junto às famílias dos prematuros. Os sujeitos do estudo foram selecionados utilizando-se a amostragem por conveniência, a partir da consulta à totalidade dos indivíduos e de acordo com a disponibilidade e o interesse na participação.

Foram entrevistados nove profissionais da equipe de enfermagem atuantes em diferentes turnos de trabalho, sendo cinco enfermeiros e quatro técnicos de enfermagem de todos os turnos, que prestam assistência direta aos recém-nascidos e/ou suas famílias na UTIN e na UCIN. Para a coleta de dados, utilizou-se um roteiro semiestruturado com as seguintes questões norteadoras: $\mathrm{O}$ que você entende por processo de alta hospitalar? Que orientações você considera importantes no preparo da família para a alta do prematuro?

As entrevistas foram realizadas nas unidades neonatais do hospital escola em estudo, nos meses de maio a julho de 2011. Estas foram transcritas na íntegra e, posteriormente, submetidas a sucessivas leituras dos depoimentos. Para a análise dos dados, utilizou-se referencial metodológico da análise de conteúdo ${ }^{(8)} \mathrm{e}$, a partir do processo de inferência e de interpretação dos relatos, e da organização destes a partir de suas unidades de significado, foi possível definir duas categorias temáticas principais.

Foram respeitados os preceitos éticos contidos na Resolução nº 196/96 do Conselho Nacional de Saúde do Ministério 
da Saúde e a coleta de dados se deu após aprovação pelo Comitê Permanente de Ética em Pesquisa Envolvendo Seres Humanos da Universidade Estadual de Maringá, sob Parecer $\mathrm{n}^{\circ}$ 059/2011. Com o escopo de garantir o anonimato dos sujeitos, utilizou-se a identificação por letras referentes às categorias profissionais seguidas de um número indicativo da ordem de realização da entrevista: Enfermeiros (E1...) e Técnicos de Enfermagem (TE1...).

\section{RESULTADOS E DISCUSSÃO}

Os nove sujeitos do estudo eram do sexo feminino, com idades variando entre 36 e 50 anos, e tempo médio de atuação nas unidades neonatais de 11,2 anos. As cinco enfermeiras entrevistadas fizeram de um a três cursos de especialização. As especializações incluíram as seguintes áreas: duas em saúde coletiva, três em fisiologia humana e uma em administração dos serviços de enfermagem e outra em obstetrícia. Com relação aos técnicos, estes apresentavam apenas a formação básica para técnico de enfermagem.

Do processo de análise dos relatos provenientes das entrevistas, depreenderam-se duas categorias temáticas: Orientações e estratégias profissionais acerca do preparo da família para a alta do prematuro e Dificuldades e potencialidades no espaço da atenção neonatal.

\section{Orientações e estratégias profissionais acerca do preparo da família para a alta do prematuro}

No período de observação que antecedeu a realização das entrevistas, constatou-se que nas unidades neonatais não há rotinas formalizadas para atendimento e preparo da família para a alta hospitalar do bebê. As orientações realizadas às famílias foram pontuadas por metade dos profissionais entrevistados, como responsabilidade de todos os membros da equipe de saúde, incluindo médicos, equipe de enfermagem, fonoaudióloga e todos os envolvidos no cuidado ao RN, o que confirma o preditivo encontrado na literatura ${ }^{(2)}$.

Eu acho que o médico, os enfermeiros, toda a equipe [devem realizar orientações à família]. E quando a criança precisa da fono, ela deve fazer o trabalho dela, então é a equipe multiprofissional mesmo (E1).

As orientações realizadas pelos profissionais se mostram pautadas, principalmente, em cuidados de higiene, conforto e aleitamento materno, corroborando com outros estudos que destacam essas temáticas de orientação ${ }^{(9-10)}$. Todos os entrevistados referiram os cuidados de higiene e o incentivo ao aleitamento materno como elementos em seu processo de orientação para alta, conforme demonstram os depoimentos a seguir:

São [orientados] mais os cuidados com banho, higiene, cuidados com temperatura e horário de alimentação (TE1).

[...] [bebê] recebendo dieta por sonda, a gente ensina como que ela vai passar. Se vai mamar no peito, a gente já começa a colocar no peito e ensina ela como que vai dar mamá. Os cuidados de banho, de proteção, de orientação de decúbito, de repouso (E1).

Outros cuidados abordados na orientação e que foram destacados pelos profissionais incluíram: o uso de gavagem, necessidade do toque e cuidados na manipulação do bebê, citados por quatro profissionais; posicionamento da criança, medicação e retorno para consulta com especialista foram discriminados por três entrevistados; cuidados em caso de engasgo e oferta de leite no copo foram referidos por dois profissionais; acompanhamento pela UBS na puericultura, prevenção de assaduras, verificação de temperatura e importância da vacinação foram citados apenas uma vez.

Cabe destacar que o significado do cuidar parece diferir entre os atores sociais envolvidos nesse processo. Em entrevistas realizadas junto às mães de prematuros durante a internação na UCIN desse mesmo hospital, como parte do projeto maior em que este estudo está inserido, percebeu-se que o conceito de "cuidar" das mães é diferente do expresso pelos profissionais. Para as mães, cuidar está relacionado ao sentimento de afeição, enquanto os profissionais relacionam o cuidado à execução de procedimentos técnicos, ao atendimento das necessidades fisiológicas da criança e à orientação da família.

Cuidar de um bebê é atender todas as necessidades que ele apresenta. Tanto no cuidado com o bebê quanto na orientação com a família (E2).

Ao serem questionados sobre a definição do processo de preparo para a alta, profissionais entendiam-no como "o momento em que a criança está pronta para ir para casa". Entretanto, os sujeitos referiram que as orientações com a mães devem ser realizadas a partir do momento em que o bebê é admitido na unidade e/ou sempre que a mãe estiver acompanhando o filho, ratificando assim, a necessidade de propiciar o contato precoce do bebê com a família, conforme se pode depreender nas falas a seguir.

O preparo para a alta hospitalar na neo já começa na admissão da criança, por serem crianças prematuras ou com má formação, a gente já começa a trabalhar com a família os cuidados desse bebê (E3).

O processo de alta hospitalar é a preparação da família para receber o bebê em casa, quanto aos cuidados, às medicações [...] (E2).

O entendimento do processo de alta como uma ação contínua que se inicia na internação do bebê também é defendido por outros autores ${ }^{(2,10)}$. Embora a participação dos pais dentro da UTIN seja limitada em função da condição clínica instável do bebê, o que muitas vezes impossibilita a manipulação deste, percebe-se a iniciativa de alguns profissionais em propiciar à mãe oportunidades de participar do cuidado ao filho.

Já que aqui elas [mães] não são visita, eu estimulo o cuidado, coloco criança intubada no colo da mãe, quando a 
mãe tem condição para isso. Eu dou banho de imersão em criança intubada e sempre quando os pais estão presentes, eu conto com eles (E3).

Os benefícios do contato mãe-bebê foram evidenciados em estudo que investigou estados comportamentais de recém-nascidos pré-termo (RNPT) em suporte ventilatório durante o cuidado mãe canguru (CMC). Identificou-se que a prática do método canguru em bebês intubados favoreceu o sono profundo e contribuiu com significativa diminuição da dor nos $\mathrm{RN}^{(11)}$. Tal constatação reforça a recomendação da utilização do Método Canguru no cuidado ao RNPT, agregando o cuidado ao bebê, assistência aos pais e à família extensa ${ }^{(12)}$.

O credenciamento do hospital em estudo à Iniciativa Hospital Amigo da Criança (IHAC) se revelou nas práticas de valorização ao aleitamento materno, na medida em que se reconhece sua relevância para o crescimento e desenvolvimento do RNPT. A IHAC foi idealizada em 1990 com o intuito de promover, proteger e apoiar a alimentação adequada de lactentes e crianças na primeira infância. Esse programa enfatiza o incentivo à amamentação exclusiva até o sexto mês de vida, regulamentado pelo exercício dos Dez Passos para o Sucesso do Aleitamento. Para qualificação da instituição como Hospital Amigo da Criança se exige o ajustamento das práticas profissionais no cumprimento desses $\operatorname{passos}^{(13)}$.

Pelo hospital ser amigo da criança e por ser muito importante para o prematuro o aleitamento materno, a gente trabalha assim, muito em cima do aleitamento (TE2).

O atendimento dos Dez Passos Para o Sucesso do Aleitamento $^{(14)}$ parece estar difundido no cotidiano dos profissionais, visto que, nas entrevistas, as orientações relacionadas à amamentação se referiam aos passos preconizados, com maior destaque para a administração do leite no copo, preterindo-se o uso de mamadeiras e chupetas durante o período de internação.

A principal estratégia de preparo da família para a alta hospitalar revelada nos depoimentos foi a inserção precoce da família no processo de cuidado, sendo tal prática referenciada por seis entrevistados. Conforme enfatizado pelos sujeitos deste estudo, o preparo para a alta hospitalar tem por objetivo capacitar as mães, tendo como ponto de partida as inseguranças e as especificidades de cada binômio, proporcionando, assim, maior autonomia às mães dentro da unidade neonatal. A inserção da família nos cuidados cotidianos do filho dentro das unidades neonatais visa também ao estabelecimento de vínculo com o bebê e ao reforço da confiança materna para realizar os cuidados no ambiente domiciliar ${ }^{(2,15)}$.

Tem mãe que abre a incubadora, pega (o bebê), põe no peito, fica com a criança no colo, então principalmente a gente trabalha com a mãe pra ela ter essa autonomia (TE2).

O envolvimento das mães nos cuidados de higiene e conforto do bebê se mostra como uma estratégia capaz de minimizar medos e angústias vivenciados por elas durante $\mathrm{O}$ período de internação do filho, diminuindo o sofrimento e contribuindo para o seu fortalecimento, no que tange ao exercício de seu papel materno. Tal participação reforça a compreensão da mãe de que ela também está contribuindo para o reestabelecimento da saúde do bebê ${ }^{(3)}$.

O processo de trabalho da enfermagem deve ser conduzido visando à autonomia dos pais. Para alcançar tal objetivo, as diretrizes do Programa Nacional de Humanização, instituído como política de saúde, reforçam a necessidade de fortalecer o trabalho em equipe multiprofissional e contribuir na construção da autonomia dos sujeitos atendidos na rede do Sistema Único de Saúde ${ }^{(16)}$.

O acolhimento dos pais nas unidades neonatais é essencial nesse sentido, cooperando inclusive com a percepção do profissional acerca das necessidades dos pais e fornecimento de informações que possam diminuir as ansiedades destes ${ }^{(17)}$. Outro estudo destaca que o acolhimento envolve algumas atitudes do profissional de enfermagem como "ter disponibilidade e sensibilidade, ser empático e extrovertido, aceitar a mãe na condição que ela se apresenta, ter envolvimento e responsabilidade, afastando-se de uma postura rígida" ${ }^{\prime(3)}$. Estes aspectos foram abordados por uma técnica de enfermagem:

Eu acho que a convivência da mãe dentro da UTI é importante, mas ela tem que ser bem acolhida, tem que vir e se sentir a vontade para tirar as dúvidas, pra ela aprender, pra conseguir se sentir acolhida pela equipe (TE1).

O diálogo como ferramenta no preparo da família foi citado por alguns profissionais, sendo este fundamental no estabelecimento de confiança na relação entre os profissionais-família-bebê, contribuindo no estabelecimento de vínculos. Estudo realizado com familiares de pacientes internados em UTIN identificou que as necessidades de segurança e informação têm maior relevância dentre todas as outras, visto que a falta de informações adequadas acarreta em sentimentos de insegurança e de ansiedade, podendo prejudicar as famílias no enfrentamento da situação ${ }^{(17)}$.

Como pode depreender no discurso a seguir, os profissionais de enfermagem sentem prazer ao realizar o cuidado ao RN e almejam não apenas a melhora da criança, mas também que esse bebê encontre condições ideais de cuidado e acompanhamento após a alta hospitalar, destacando, desse modo, a importância de se assegurar o caráter de continuidade dos cuidados.

Eles estão brigando pra viver né, então é por isso que eu gosto mais de cuidar dos prematuros [...] Muitas [mães] saem daqui já preparadas, mas muitas a gente sabe que não têm estrutura social e um suporte familiar pra acompanhar a criança (TE2).

O desejo intrínseco dos profissionais em "minimizar o sofrimento, a dor e as sequelas do recém-nascido e promover o vínculo afetivo entre eles o os pais"(18) foi identificado em um estudo como uma expectativa motivacional na prática dos enfermeiros ${ }^{(18)}$. 
O prematuro hospitalizado passa por diferentes estágios de evolução clínica, as orientações e condutas a serem realizadas para a família vão depender de cada criança, das necessidades de cuidado, história familiar, condições socioeconômicas e da patologia. Portanto, o planejamento de alta não pode prescindir de uma avaliação cuidadosa de todos esses fatores, das necessidades do prematuro e de sua família. A fim de proporcionar proteção e os cuidados adequados ao filho, os pais devem estar conscientes de que as necessidades do RNPT diferem daquelas apresentadas pelo bebê nascido a termo, em especial no que concerne a padrões de crescimento e de desenvolvimento ${ }^{(10)}$.

\section{Dificuldade e potencialidades no espaço da atenção neonatal}

Por meio deste estudo os profissionais apontaram dificuldades vivenciadas durante o processo de preparo da família para a alta do prematuro. Dentre elas, a ausência dos pais nas unidades neonatais se destacou na totalidade das entrevistas. Tal situação foi justificada pelos sujeitos, apontando fatores como: dificuldade de deslocamento das famílias, por residirem em outro município e dependerem do transporte oferecido pela prefeitura do município onde residem, para o deslocamento até o hospital; ter outros filhos pequenos em casa e que necessitam de cuidados. Outro estudo realizado com mães de prematuros também referiu tais dificuldades ${ }^{(19)}$.

Uma das coisas que a gente tem bastante dificuldade aqui é a ausência da mãe. Eles dependem às vezes de uma ambulância, e às vezes é muito longe, não pode passar o dia aqui, vem a cada dois, três dias [...] não que a mãe não queira aprender, mas precisa de uma ajuda, de alguém que cuide da criança dela que está em casa (TE3).

A ausência da família durante a internação do prematuro dificulta a implementação de ações voltadas à educação em saúde no período da hospitalização, que por sua vez, implica despreparo desta para os cuidados domiciliares após a alta hospitalar.

A gente tá retomando no projeto canguru as reuniões com a família. E por incrível que pareça em três semanas conseguimos fazer só duas [reuniões] porque não tem mãe (E3).

A sugestão proposta por um sujeito deste estudo, no intuito de solucionar tal situação, foi que o hospital pudesse disponibilizar uma casa de apoio ou alojamento para as mães de prematuros residentes em outros municípios, visto que tal medida facilitaria a permanência das mães nas unidades neonatais e, por conseguinte, permitiria ampliar as oportunidades de ensino durante a permanência das mães no acompanhamento ao filho.

Elas ficarem um dia aqui com o bebê e a noite terem um local onde pudessem descansar, jantar, e de manhã novamente estar aqui. Para nós seria ótimo e para a mãe também (TE3).

Esta assertiva ratifica os resultados de um estudo realizado em um hospital maternidade que conta com a estratégia de alojamento para as mães ${ }^{(20)}$. Nessa experiência, o alojamento emerge como um fator importante não apenas para favorecer o acompanhamento materno ao filho internado, mas também se concretiza como um espaço terapêutico marcado por vivências de solidariedade entre iguais, que podem trocar experiências e se apoiarem mutuamente, reforçando a esperança nesse momento em que estão fragilizadas.

O acesso livre para permanência dos pais na unidade neonatal durante todo o dia emergiu nas falas como uma potencialidade do serviço visto que viabiliza o fortalecimento de vínculo da família com o bebê.

Antigamente, pelas mães e pais virem só em horário de visita, esse elo (com o bebê) era cortado e depois, para que a gente pudesse fazer essa religação, era muito mais difícil [...] A gente trabalha muito em contato com os pais, e eles se apegam bastante na gente (TE2).

Tal possibilidade de permanência dos pais também se configura como elemento primordial no preparo da para a alta do prematuro, pois viabiliza a assistência à família e amplia as oportunidades de ensino/aprendizagem. Neste estudo, o vínculo estabelecido entre o profissional e a família também insurgiu como um componente gerador de satisfação profissional.

Outro estudo também enfatizou a relevância da presença da família na UTIN, possibilitando o cuidado diferenciado, facilitando uma maior percepção acerca das perspectivas da família, inserindo os pais nos cuidados (principalmente por meio do toque e do aleitamento materno); e estimulando o vínculo entre os pais e o bebêe $\hat{e}^{(18)}$.

A equipe deve procurar adequar a rotina para favorecer a participação da família nos cuidados e na tomada de decisões relativas ao filho internado. Para tanto, a parceria entre pais e equipe é considerada como elemento fundamental na efetivação do cuidado, e no compartilhamento de saberes e práticas, de maneira a fortalecer as habilidades e as capacidades de cada família(19).

A integração entre as diferentes categorias profissionais também foi sugerida como estratégia para melhorar o atendimento à família. A coesão no trabalho dos membros da equipe multiprofissional e interdisciplinar é essencial para otimizar a integralidade da assistência à criança/família e garantir uniformidade das informações transmitidas.

[...] maior integração com a equipe mesmo. Acho que as crianças vão ganhar e nós também, porque os treinamentos (com as famílias) a gente tá fazendo (E3).

Estudos realizados em unidades neonatais também revelaram falta de sincronia e integração entre as diferentes categorias profissionais que atendem ao recém-nascido, influenciando negativamente na assistência de enfermagem e suscitando insatisfação nos profissionais ${ }^{(10,18)}$.

A inexistência de rotinas escritas e de registros sistemáticos em prontuário, no tocante às ações relativas ao preparo da família para a alta, foi evidenciada no processo de observação 
não participante, em todos os turnos acompanhados. Vale ressaltar que a sistematização da assistência poderia ser concretizada a partir de um protocolo que direcionasse as orientações essenciais para instrumentalizar a família.

No sentido de suprir essa lacuna, um dos entrevistados sugeriu a estratégia de sistematização da assistência utilizando a "adoção das famílias" pelos profissionais. Esta se mostra também como uma prática viável, passível de execução sem a necessidade de grandes mobilizações na rotina. Ademais, sua principal justificativa se baseia no fato de que tal estratégia potencializa as relações de vínculo entre profissional-mãe, podendo otimizar o preparo da família.

Sistematizar a assistência talvez [...] porque a gente iria se cobrar mais pra ensinar, ao ter alguém responsável pra fazer essa orientação [...] (E1).

Embora a prática da enfermagem esteja vinculada ao esforço contínuo para capacitar as famílias, fatores intrínsecos às progenitoras foram enfatizados pelos sujeitos como dificultadores para as ações de educação em saúde durante o processo da alta. Dentre esses fatores, foram citados: a drogadição materna, a baixa escolaridade e/ou deficiências cognitivas que dificultam a compreensão das informações, e a maternidade na adolescência.

Em relação à educação materna, há referências na literatura de que a baixa escolaridade interfere na capacidade de aprendizado, sendo primordial que o profissional de enfermagem se empenhe para adaptar recursos que viabilizem a capacitação materna ${ }^{(9)}$.

\section{CONSIDERAÇÕES FINAIS}

Este estudo possibilitou compreender a prática da equipe de enfermagem atuante em unidades neonatais acerca do processo de alta junto às famílias. Como estratégias reconhecidas no processo de ensino foram elencadas a inserção precoce da família nos cuidado de higiene e conforto requeridos pelo recém-nascido internado, incentivo ao aleitamento materno e outras orientações relacionadas à alimentação, à medicação e à necessidade de seguimento ambulatorial e na rede de atenção primária, após alta hospitalar.

No âmbito das dificuldades encontradas, os resultados foram condizentes com dados encontrados na literatura. Destacou-se como principal problema, a ausência das mães no acompanhamento contínuo do filho internado. Emergiram, ainda, outras dificuldades para a efetivação desse processo, tais como a falta de sistematização do preparo para alta, além de fatores intrínsecos às mães, como a baixa escolaridade, a drogadição e a maternidade na adolescência. Quanto às potencialidades do serviço, apontadas pelos profissionais neste estudo, destacaram-se o livre acesso dos pais às unidades neonatais e as práticas promotoras da humanização da assistência como, por exemplo, as diretrizes preconizadas pela IHAC.

Este estudo possibilitou depreender-se que a filosofia do cuidado centrado na família está incutida nas práticas da equipe de enfermagem, fato que potencializa as oportunidades de ensino/aprendizagem. As potencialidades e limitações apontadas por este estudo revelam que o processo da assistência é dinâmico, necessitando de constantes reajustes e adequações para atender com excelência e integralidade o RN e sua família.

\section{REFERÊNCIAS}

1. Cruz ATCT, Dodt RCM, Oriá MOB, Alves MDS. Enfermagem em unidade de terapia intensiva neonatal: perfil da produção científica brasileira. Cogitare Enferm. 2011;16(1):141-7.

2. Souza JC, Silva LMS; Guimarães TA. Preparo para a alta hospitalar de recém-nascido em unidade de tratamento intensivo neonatal: uma visão da família. Pediatria (São Paulo). 2008;30(4):217-27.

3. Fraga TF, Amante LN, Anders JC, Padilha MICS, Henckemaeir L, Costa R, et al. Percepção das mães sobre o processo comunicacional na unidade de terapia intensiva neonatal. Rev Eletrônica Enferm [periódico na internet]. 2009 [acesso em 22 nov 2011];11(3):612-9. Disponível em: http://www.fen.ufg.br/revista/v11/n3/v11n3a19.htm.

4. Souza NL, Pinheiro-Fernandes AC, Clara-Costa IC, Cruz-Enders B, Carvalho JB, Silva ML. Domestic maternal experience with preterm newborn children. Rev Salud Pública. 2010;12(3):356-67.

5. Costa MCG, Arantes MQ, Brito MDC. A UTI neonatal sob a ótica das mães. Rev Eletrônica Enferm. [periódico na internet]. 2010 [acesso em 22 nov 2011];12(4):698704. Disponível em: http://www.fen.ufg.br/revista/v12/ n4/v12n4a15.htm.
6. Alves VH, Costa SF, Vieira BDG. A permanência da família em Unidade de Terapia Intensiva Neonatal: imaginário coletivo dos enfermeiros. Ciênc Cuid Saúde. 2009;8(2):250-56.

7. Tamez RN, Silva MJP. Enfermagem na UTI neonatal. 2. ed. Rio de Janeiro: Guanabara Koogan; 2002.

8. Bardin L. Análise de conteúdo. 4. ed. Lisboa: Edições 70; 2010.

9. Lélis ALPA, Machado MFAS, Cardoso MVLML. Educação em saúde e a prática de enfermagem ao recém-nascido prematuro. Rev RENE. 2009;10(4):60-9.

10. Gaíva MAM, Neves AQ, Silveira AO, Siqueira FMG. A alta em unidade de cuidados intensivos neonatais: perspectiva da equipe de saúde e de familiares. REME Rev Min Enferm. 2006;22(3):387-92.

11. Azevedo VMGO, David RB, Xavier CC. Cuidado mãe canguru em recém-nascidos pré-termo sob suporte ventilatório: avaliação dos estados comportamentais. Rev Bras Saúde Mater Infant. 2011;11(2):133-38.

12. Ministério da Saúde. Secretaria de Atenção à Saúde. Atenção à saúde do recém-nascido: guia para os profissionais de saúde. Cuidados Gerais. V.1 Serie A. Normas e Manuais técnicos. Brasília, DF: Ministério da saúde; 2011. 
13. Ministério da Saúde. Secretaria de Atenção à Saúde. Iniciativa Hospital Amigo da Criança: revista, atualizada e ampliada para o cuidado integrado: módulo 1: histórico e implementação. Brasília, DF: 2008.

14. Ministério da Saúde (Brasil). Portaria $n^{\circ}$. 756, de 16 de dezembro de 2004. Estabelece as Normas para o processo de habilitação do hospital amigo da criança integrante do sistema único de saúde - SUS [portaria na internet]. Diário Oficial da União [acesso em 22 nov 2011]. Disponível em: http://portal.saude.gov.br/portal/arquivos/pdf/ Port $\% 20 \% 20756 \% 20$.pdf

15. Martínez JG, Fonseca LMM, Scochi CGS. The participation of parents in care of premature children in neonatal unit: meanings attributed by health team. Rev. Latino-Am. Enfermagem. [periódico na internet]. 2007 [acesso em 18 out 2011];15(2):230-8. Disponível em: http://www.scielo. br/pdf/rlae/v15n2/pt_v15n2a08.pdf.

16. Ministério da Saúde. Secretaria de Atenção à Saúde. Política Nacional de Humanização. Documento Base para
Gestores e Trabalhadores do SUS. 2. ed. Brasília: Ministério da Saúde; 2004.

17. Soares LO, Santos RF, Gasparino RC. Necessidades de familiares de pacientes internados em unidade de terapia intensiva neonatal. Texto \& Contexto Enferm. 2010;19(4):644-50.

18. Montanholi LL, Merighi MAB, Jesus MCP. Atuação da enfermeira na unidade de terapia intensiva neonatal: entre o ideal, o real e o possível. Rev Latino-Am Enferm [periódico na internet];2011 [acesso em 18 out 2011];19(2):[8 telas]. Disponível em: http://www.scielo.br/pdf/rlae/v19n2/pt_11.pdf.

19. Gaíva MAM, Scochi CGS. A participação da família no cuidado em UTI neonatal. Rev Bras Enferm. 2005;58(4):444-8.

20. Araújo BBM, Rodrigues BMRD. Vivências e perspectivas maternas na internação do filho prematuro em Unidade de Tratamento Intensivo Neonatal. Rev Esc Enferm USP. 2010;44(4):865-72. 